\title{
Comparison between the Results of Management of Recent Unstable Proximal Femoral Fractures by Proximal Femoral Nailing and Locked Plating
}

\author{
M.A.Mashhour, A.A.Ahmed, E.M.Bayoumyand S.M.Salem \\ Orthopedic Surgery Dept., Faculty of Medicine, Benha Univ., Benha, Egypt \\ E-Mail:Sherif@gmail.com
}

\begin{abstract}
Careful adjustment of the intertrochanteric cracks and early activation of the patients are the ideal treatment to forestall the confusions of delayed immobilization, aside from in patients with clinical issues in whom medical procedure is contraindicated. The Dynamic hip screw (DHS) has been the norm and the best archived embed in rewarding intertrochanteric breaks and in a few randomized preliminaries it has been related with lower difficulties and reoperation rates. Also, it is a more affordable embed, however hypothetically it has a biomechanical drawback in view of a more extensive separation between the weight bearing pivot and the embed A sum of 20 instances of shaky proximal femoral breaks were incorporated, and they were partitioned into two equivalent gatherings; the principal bunch experienced PFN, while the other one experienced LP. Follow up visits was at 1st,3rd,6th weeks and third and sixth months in outpatient facility and results were recorded. Altered Harris Hip Score had a middle of 88 and 85 in the femoral nail and bolted plate bunches separately $(\mathrm{p}=$ 0.114). Postponed association was experienced uniquely in one case in the bolted plate gathering, while it was not experienced in the other gathering $(\mathrm{p}=0.345)$. Radiological assessment uncovered a middle score of 3 in both examination gatherings. all the inserts in their own privilege are magnificent modalities in the administration of unsteady proximal cracks of the femur. Precarious proximal femoral cracks with rotational mal-arrangement issues were dealt with best by PFN. Precarious proximal femoral cracks particularly with expanded comminution do give a choice to be fixed by LP.
\end{abstract}

\section{Introduction}

An expansion in the old populace has brought about rising the rate of hip breaks in numerous pieces of the world. Expanded life span, along with osteoporosis and decrepit solid inadequacy, may clarify the expanding number of patients with hip breaks [1]. Later proof recommends that varieties in Proximal Femoral Geometry likewise assume a significant job in hip break etiology [2].

The trademark morphology of the proximal limit of the femur and the muscle equalization of the hip are factors that make weight bearing conceivable among patients. Ongoing examinations have been directed with the aim of demonstrating the connection between crack of the proximal limit of the femur and the anatomical arrangement of the hip [3].

Around half of hip cracks are intertrochanteric breaks (extracapsular cracks) and by and large happen because of lowvitality injury, for example, basic falls in cutting edge age, though they are brought about by high-vitality injury in youthful people, and the over-burden on the proximal furthest point of the femur creates distorting powers that bring about break occurrence [4].

Careful adjustment of the intertrochanteric breaks and early activation of the patients are the ideal treatment to forestall the difficulties of delayed immobilization, aside from in patients with clinical issues in whom medical procedure is contraindicated [5]. The investigation of proximal femoral morphology encourages the system of preoperative arranging and diminishes the danger of injury of trochanteric encompassing structures [6].

The Dynamic hip screw (DHS) has been the norm and the best reported embed in rewarding intertrochanteric breaks and in a few randomized preliminaries it has been related with lower confusions and reoperation rates. Likewise, it is a more affordable embed [7], yet hypothetically it has a biomechanical burden as a result of a more extensive separation between the weight bearing pivot and the embed [8].

As of late, various investigates introduced the geometry of trochanteric district and proximal femur to improve the plan of new embeds, concerning their anatomical tourist spots, structure and dispersion of their hard tissue. Structures of Proximal femoral nail (PFN) and Locked plate (LP) are found to go about as appropriate inserts for proximal femoral geometry for zone breaks obsession explicitly for those precarious cracks [9].

At long last, centrality of the proximal femoral morphology has been examined to find in the event that we can improve medical procedure planning and make it increasingly productive. This has empowered an increasingly broad investigation of randomized preliminaries on the utilization of DHS gadgets for the obsession of intertrochanteric cracks in grown-ups and its impact on typical proximal femoral morphology [10].

The point of this investigation was to think about between the consequences of the treatment of temperamental proximal femoral 
cracks in grown-ups utilizing Proximal Femoral Nail (PFN) and Proximal Femoral Locked Plate (PFLP) and assess radiologically and clinically the impact of the inserts on ordinary proximal femoral morphology.

\section{Patient and Method}

This work is a prospective study of twenty pateints with unstable proximal femur fractures treated by proximal femoral nail and proximal femoral locked plate at Banha university Hospital and El-Menshawy Hospital and during the period from July 2017 to December 2018.

Inclusion criteria was Skeletally mature patients group (Above $16 \mathrm{ys}$ ) from both sex with Unstable fractures according to AO classification as following :

\section{A1: Peri-trochanteric simple:}

- 31-A1.1: Along intertrochanteric line

- 31-A1.2: Through greater trochanter

- 31-A1.3: Below lesser trochanter

A2: Peri-trochamteric multifragmentary:

- 31-A2.1: With one intermediate fragment

- 31-A2.2: With several intermediate fragments

- 31-A2.3: Extending more than $1 \mathrm{~cm}$ below lesser trochanter

\section{A3: Intertrochanteric:}

- 31-A3.1: Simple oblique

- 31-A3.2: Simple Transverse

- 31-A3.3: Multifragmentary

An expansion in the old populace has brought about rising the rate of hip breaks in numerous pieces of the world. Expanded life span, along with osteoporosis and decrepit solid inadequacy, may clarify the expanding number of patients with hip breaks [1]. Later proof recommends that varieties in Proximal Femoral Geometry likewise assume a significant job in hip break etiology [2].

The trademark morphology of the proximal limit of the femur and the muscle equalization of the hip are factors that make weight bearing conceivable among patients. Ongoing examinations have been directed with the aim of demonstrating the connection between crack of the proximal limit of the femur and the anatomical arrangement of the hip [3].

Around half of hip cracks are intertrochanteric breaks (extracapsular cracks) and by and large happen because of lowvitality injury, for example, basic falls in cutting edge age, though they are brought about by high-vitality injury in youthful people, and the over-burden on the proximal furthest point of the femur creates distorting powers that bring about break occurrence [4].
Careful adjustment of the intertrochanteric breaks and early activation of the patients are the ideal treatment to forestall the difficulties of delayed immobilization, aside from in patients with clinical issues in whom medical procedure is contraindicated [5]. The investigation of proximal femoral morphology encourages the system of preoperative arranging and diminishes the danger of injury of trochanteric encompassing structures [6].

The Dynamic hip screw (DHS) has been the norm and the best reported embed in rewarding intertrochanteric breaks and in a few randomized preliminaries it has been related with lower confusions and reoperation rates. Likewise, it is a more affordable embed [7], yet hypothetically it has a biomechanical burden as a result of a more extensive separation between the weight bearing pivot and the embed [8].

As of late, various investigates introduced the geometry of trochanteric district and proximal femur to improve the plan of new embeds, concerning their anatomical tourist spots, structure and dispersion of their hard tissue. Structures of Proximal femoral nail (PFN) and Locked plate (LP) are found to go about as appropriate inserts for proximal femoral geometry for zone breaks obsession explicitly for those precarious cracks [9].

At long last, centrality of the proximal femoral morphology has been examined to find in the event that we can improve medical procedure planning and make it increasingly productive. This has empowered an increasingly broad investigation of randomized preliminaries on the utilization of DHS gadgets for the obsession of intertrochanteric cracks in grown-ups and its impact on typical proximal femoral morphology [10].

The point of this investigation was to think about between the consequences of the treatment of temperamental proximal femoral cracks in grown-ups utilizing Proximal Femoral Nail (PFN) and Proximal Femoral Locked Plate (PFLP) and assess radiologically and clinically the impact of the inserts on ordinary proximal femoral morphology.

\section{Proximal femoral nail}

The more prominent trochanter is recognized by palpation and an entry point of roughly $5 \mathrm{~cm}$ is made proximal to the head of the trochanter. The cut is developed, through the sash lata, parting the abductor muscles for roughly $3 \mathrm{~cm}$ promptly over the tip of the more prominent trochanter to uncover the tip. Utilizing the finger, the tip of the trochanter is recognized and the right entery point is 
choosen at the tip of the more prominent trochanter.

In the parallel plane, the drill must be set at the intersection of the front third and back $66 \%$ of the head of the more prominent trochanter. The section point ought to be at the tip of the more noteworthy trochanter. On the off chance that it is extremely average, (for example, in the piriform fossa), the bended nail won't go down the pole appropriately, with the risk of cracking the femur. On the off chance that the tip of the bended borer is put excessively far along the side, there is an extraordinary risk of breaking the more prominent trochanter.

At the point when the passage point is done, the reamer control wire must be set in position in the wake of evacuating the bit. This guide wire permits the proximal femur to be readied utilizing adaptable force reamers. The reamer direct wire will go from passage point into the more noteworthy trochanter in the pole of the femur. Reaming is proceeded untill the medullary trench is reamed $2 \mathrm{~mm}$ bigger than the expected nail measurement.

Plan trochanteric district by reaming it up to $17 \mathrm{~mm}$ to embed proximal piece of proximal femoral nail which is more extensive than the remainder of the nail. Reaming of trochanteric district ought not surpass lower some portion of lesser trochanter.

Presently the nail is presented utilizing dance handle. Mallet is maintained a strategic distance from all together not to influence the break site and decrease. Nail is presented till slack screw is at the inside (or only underneath) of femoral neck.

Presently manage wire for slack screw is embedded to permit right course of slack screw.Tip of the wire must be $5 \mathrm{~mm}$ subchondral in the femoral head on the anteroback view and focal in the horizontal view

From that point forward, the guide sleeve for the slack screw manage wire will be embedded and pushed immovably till the sidelong cortex. Guide sleeve must be immovably pushed against the horizontal cortex of the femur. At that point utilize the estimation to quantify slack screw length.

Guide sleeve will be evacuated now and the slack screw penetrating will be done through the guide wire through utilizing delicate tissue defender. Reaming was finished by power penetrating in all patients Fig (46A). Boring should proceed until the stop impacts against the delicate tissue defender . Against rotatory screw likewise might be embedded to enlarge femoral head and neck dependability.

At long last, distal locking screws are embedded. Screws are chosen by their length estimations. In proximal femoral nail there is distal locking ability either static or dynamic or blend of satatic and dynamic.

\section{Proximal femoral locked plate}

The more prominent trochanter is recognized by palpation and an entry point of roughly $5 \mathrm{~cm}$ is made proximal to the head of the trochanter. The cut is developed, through the sash lata, parting the abductor muscles for roughly $3 \mathrm{~cm}$ promptly over the tip of the more prominent trochanter to uncover the tip. Utilizing the finger, the tip of the trochanter is recognized and the right entery point is choosen at the tip of the more prominent trochanter.

In the parallel plane, the drill must be set at the intersection of the front third and back $66 \%$ of the head of the more prominent trochanter. The section point ought to be at the tip of the more noteworthy trochanter. On the off chance that it is extremely average, (for example, in the piriform fossa), the bended nail won't go down the pole appropriately, with the risk of cracking the femur. On the off chance that the tip of the bended borer is put excessively far along the side, there is an extraordinary risk of breaking the more prominent trochanter.

At the point when the passage point is done, the reamer control wire must be set in position in the wake of evacuating the bit. This guide wire permits the proximal femur to be readied utilizing adaptable force reamers. The reamer direct wire will go from passage point into the more noteworthy trochanter in the pole of the femur. Reaming is proceeded untill the medullary trench is reamed $2 \mathrm{~mm}$ bigger than the expected nail measurement.

Plan trochanteric district by reaming it up to $17 \mathrm{~mm}$ to embed proximal piece of proximal femoral nail which is more extensive than the remainder of the nail. Reaming of trochanteric district ought not surpass lower some portion of lesser trochanter.

Presently the nail is presented utilizing dance handle. Mallet is maintained a strategic distance from all together not to influence the break site and decrease. Nail is presented till slack screw is at the inside (or only underneath) of femoral neck.

Presently manage wire for slack screw is embedded to permit right course of slack screw.Tip of the wire must be $5 \mathrm{~mm}$ subchondral in the femoral head on the anteroback view and focal in the horizontal view

From that point forward, the guide sleeve for the slack screw manage wire will be embedded and pushed immovably till the sidelong cortex. Guide sleeve must be immovably pushed against the horizontal 
cortex of the femur. At that point utilize the estimation to quantify slack screw length.

Guide sleeve will be evacuated now and the slack screw penetrating will be done through the guide wire through utilizing delicate tissue defender. Reaming was finished by power penetrating in all patients (Fig. 46A). Boring should proceed until the stop impacts against the delicate tissue defender . Against rotatory screw likewise might be embedded to enlarge femoral head and neck dependability.

At long last, distal locking screws are embedded. Screws are chosen by their length estimations. In proximal femoral nail there is distal locking ability either static or dynamic or blend of satatic and dynamic.

\section{Postoperative care}

As a rule, no pull channel has been required as there was insignificant seeping from the injury. All patients got post-employable antiinfection agents and low atomic weight heparin (LMWH) during their confined to bed period. Patients were permitted to sit in a bed at tenth day, flexion and expansion of ipsilateral knee at seventh day and fractional weight bearing following a month in proximal femoral nail and a month and a half in proximal femoral bolted plate. Follow up visits was at $1 \mathrm{st}, 3 \mathrm{rd}, 6 \mathrm{th}$ weeks and third and sixth months in outpatient facility and results were recorded.

\section{Results}

The mean age of the included cases was 57.7 and 59.3 years in the femoral nail and bolted plate bunches individually. In the main gathering, we included 4 guys (40\%) and 6 females $(60 \%)$, though in the other gathering, the two sexes hade a similar proportion. Both diabetes mellitus and hypertension were available in 3 and 4 cases in the examination bunches separately. The entirety of the recently talked about factors were not measurably noteworthy between the investigation gatherings $(\mathrm{p}>0.05)$.

At the point when instrument of injury was remembered for study gatherings, it was seen that method of injury is low vitality injury in $80 \%$ (half fall in restroom and $30 \%$ fall on steps) and high vitality injury in simply $20 \%$ (RTA). Fall in washroom speaks to half of method of injury $(30 \%$ in femoral nail and $20 \%$ in bolted plate separately) while fall on steps speaks to $30 \%$ with equivalent rate between both PFN and LP (15\%).

With regards to crack kinds in our investigation, non-comminuted break was the commonest one on the two gatherings (80 and $60 \%$ separately). The rest of the cases were having comminuted cracks .
Break designs are reviewed by AO grades. The two evaluations, flimsy peritrochanteric (31A-2) and opposite slanted (31A-3) are remembered for the investigation however turn around sideways cases were the dominant part .

For PFN switch slanted was 8 cases $(40 \%)$ and temperamental peritrochanteric was 2 cases $(10 \%)$ while in LP, invert angled was 7 cases $(35 \%)$ and precarious peritrochanteric was 3 caese $(15 \%)$.

Osteoporosis is remembered for both investigation gatherings. It had no critical effect in PFN (30\% osteoporotic patients and $20 \%$ non oateoporotic patients) yet its criticalness was in LP $(35 \%$ osteoporotic patients and $15 \%$ non osteoporotic patients) as it demonstrated better outcomes to fix osteoporotic breaks with LP .

The usable time was fundamentally longer in the bolted plate gathering (78 versus 52 minutes in the femoral nail gathering $-\mathrm{p}=$ 0.009). Albeit two cases in the bolted plate bunch got intra-employable blood bonding versus no cases in the other gathering, it was measurably unimportant $(\mathrm{p}=0.081)$. The cut length was longer in the bolted plate gathering (115 $\mathrm{mm}$ versus $60 \mathrm{~mm}$ in the femoral nail gathering $-\mathrm{p}<0.001)$.

Shallow careful site contamination was experienced in just 1 case $(10 \%)$ in the femoral nail gathering and it is treated with wide range anti-microbial and day by day dressing. While it was experienced in 2 cases $(20 \%)$ in the other gathering. In both, it was treated by shallow debridement and anti-microbial as per culture and affectability. Each of the three patients in the two gatherings were diabetic so $\mathrm{Hb} \mathrm{A} 1 \mathrm{c}$ was required and blood glucose level was mentioned .

Harris hip score had a middle of 88 and 85 in the femoral nail and bolted plate bunches individually $(\mathrm{p}=0.114)$. Postponed association was experienced distinctly in one case in the bolted plate gathering, while it was not experienced in the other gathering $(\mathrm{p}=0.345)$. Radiological assessment uncovered a middle score of 3 in both examination gatherings .

Embed disappointment was evaluated in both examination gatherings. $\mathrm{Z}$ impact (slack screw moves along the side and against rotatory screw relocates medially) was appeared in one case in PFN. It was overseen by re-activity in which hostile to rotatory screw was expelled and slack srew is supplanted by bigger one .

In LP, two cases indicated embed disappointment through plate breakage. In one of them, plate was broken distal to crack site yet no relocation happened so non ambulation 
period expanded and once break joined together, plate is evacuated.
For another situation plate was broken with crack dislodging so re-obsession with another LP was finished with iliac peak joining.

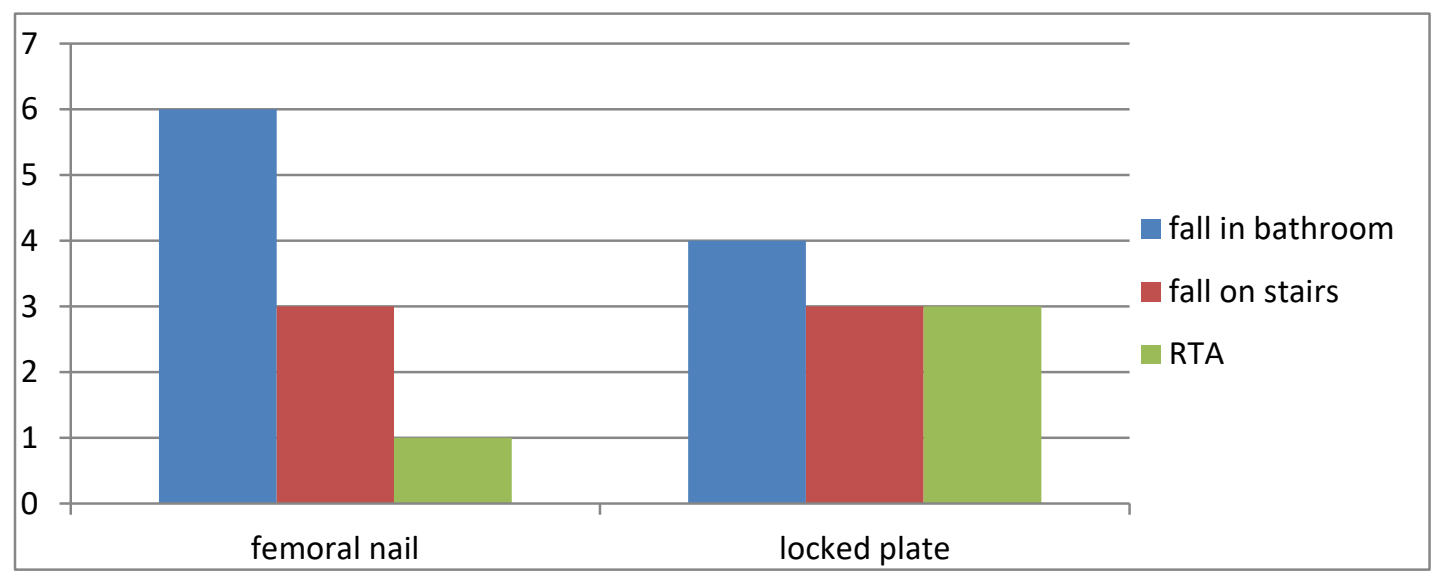

Fig (1) Mechanism of injury in the study groups.

Table (1) Operative findings.

\begin{tabular}{lccc}
\hline Variable & $\begin{array}{c}\text { Femoral nail } \\
(\mathbf{n}=\mathbf{1 0})\end{array}$ & $\begin{array}{c}\text { Locked plate } \\
(\mathbf{n = 1 0})\end{array}$ & P value \\
\hline Operative time (min.) & $52(45-60)$ & $78(70-90)$ & $0.009^{*}$ \\
Need for Tx & $0(0 \%)$ & $2(20 \%)$ & 0.081 \\
Incision length $(\mathbf{m m})$ & $60(50-80)$ & $115(100-140)$ & $<0.001^{*}$ \\
\hline
\end{tabular}

Table (2) Post-operative data.

\begin{tabular}{lccc}
\hline Variable & Femoral nail & Locked plate & P value \\
\hline Modified HHP & $88(80-95)$ & $85(79-92)$ & 0.114 \\
Delayed union & $0(0 \%)$ & $1(10 \%)$ & 0.345 \\
Radiological evaluation & $3(3-4)$ & $3(3-4)$ & 1 \\
\hline
\end{tabular}

\section{Case No. (1)}

- Patient profile: Male patient 34 years old, coach, from Alexandria, had road traffic accident and developed reversed oblique intertrochanteric fracture of the right femur. No other injuries. No pre-existing medical diseases and no previous operations. The surgery was done on the $9^{\text {th }}$ day from trauma.

- Fracture grading: Reversed oblique inter-trochanteric fracture 31-A3.

- Treatment modality: Closed insertion of PFN.

- Intra-operative difficulties: None
- Postoperative program: We delayed partial weight-bearing till $6^{\text {th }}$ postoperative day. Full loading began at 4 weeks. Total postoperative stay was 15 days.

- Follow-up period: 6 months.

- Complication: None.

- Final result: There was no infection,fracture united and consolidated. Postoperative walking level was excellent with full range of motion, minimal hip or knee pain and negative Trendelenburg sign.

- Postoperative score: 90 (Excellent) 


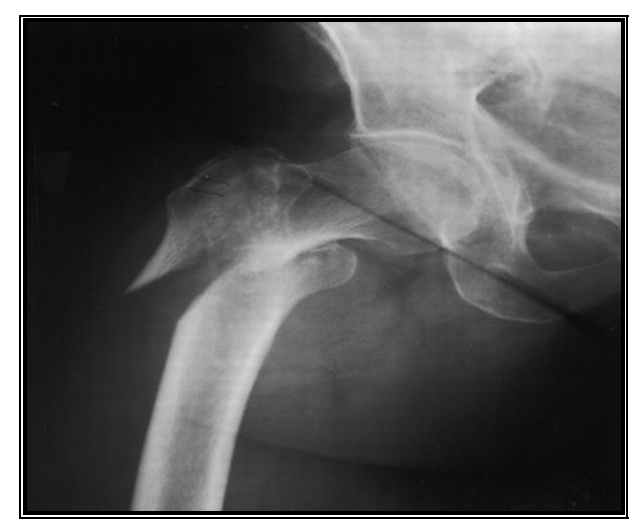

A

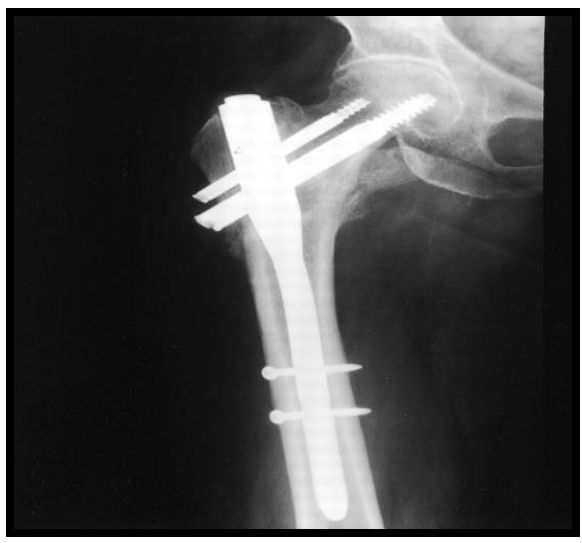

C

Fig (2) case no.1: A) Preoperative $x$-ray C) 6 months postoperative $\mathrm{x}$-ray

26 months postoperative x-ray showed good union but patient was complaining of Rt. groin pain on prolonged weight bearing. Analgesics and anti-inflammatory drugs were prescribed especially during and after activity. Rest was advised till pain subsides.

Case No. (2)

- Patient profile: Male patient 70 years old, Farmer, fall from height and developed intertrochanteric fracture with subtrochanteric extension in the right femur. He was Diabetic, Cardiac, Hypertensive. Surgery was performed after 5 days.

- Fracture grading: Unstable intertrochanteric fracture with subtrochanteric extension 31-A2

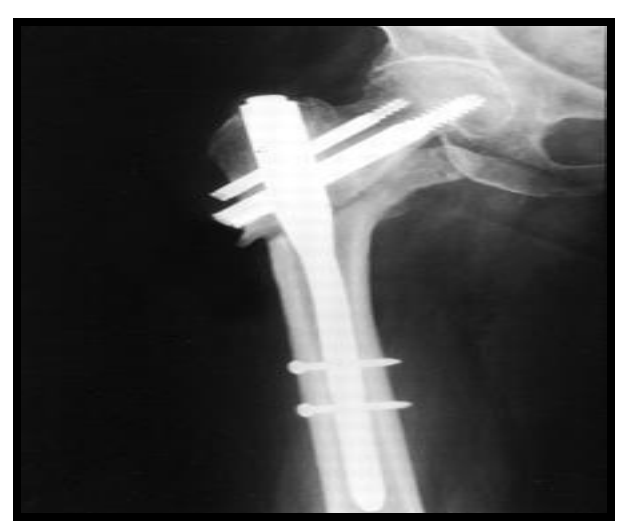

B

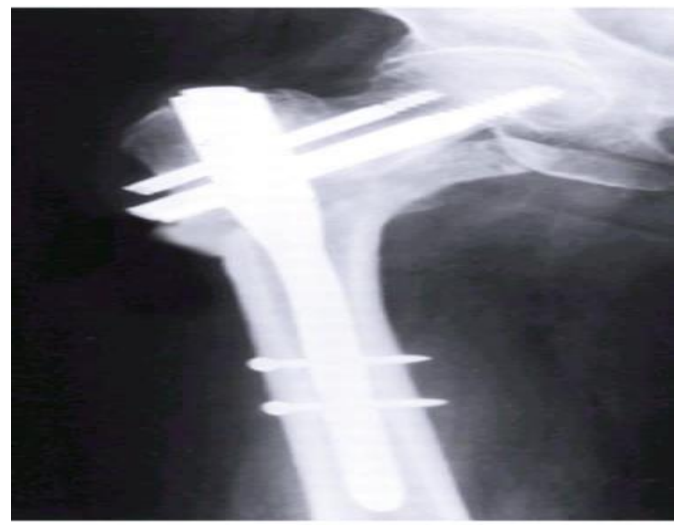

D

B) Postoperative x-ray

D) 26 months postoperative $x$-ray

- Treatment modality: ORIF by Proximal femoral locked plate.

- Postoperative program: We delayed partial weight-bearing till $6^{\text {th }}$ week postoperative. Full loading began at 8 weeks. Total postoperative stay was 7 days.

- Follow-up period: months

- Complication: Delayed union.

- Final result: There was no infection. There was mild to moderate hip pain. Postoperative walking level was normal.

- Postoperative score: 88 (Good)

- Proximal femur changes: Not significant. 


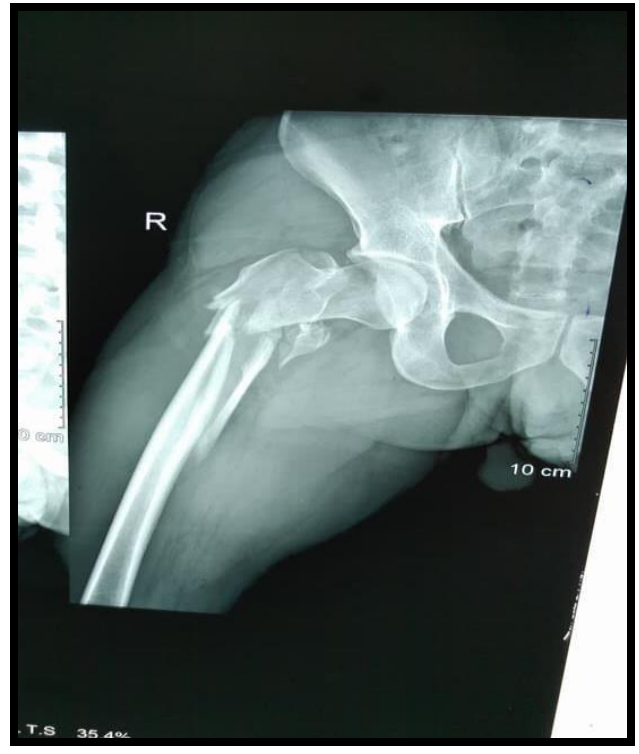

A

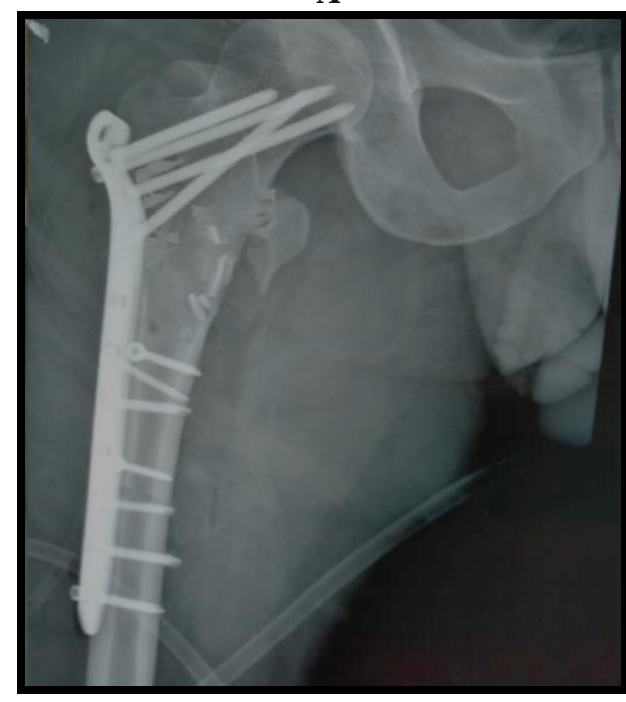

C

Fig (2) case no.2: A) Preoperative $x$-ray x-ray

23 months postoperative $\mathrm{x}$-ray showed good union but there was pain during direct pressure on the thigh and pain is aggravated by internal \& external rotation of Rt. hip.

Analgesics and anti-inflammatory drugs were prescribed and another visit for follow up is asked after one month.

If pain still presents after one month, plate will be removed and physiotherapy will be advised after inflammation subsides to strength surrounding muscles and increase ROM.

\section{Discussion}

An all out number of 20 cases who were separated into two equivalent gatherings, the main gathering were overseen by PFN while

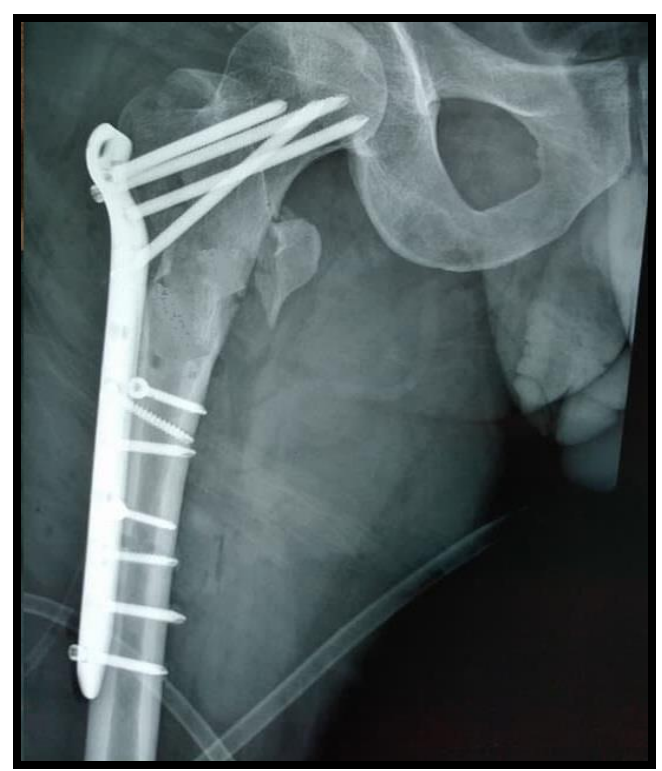

B

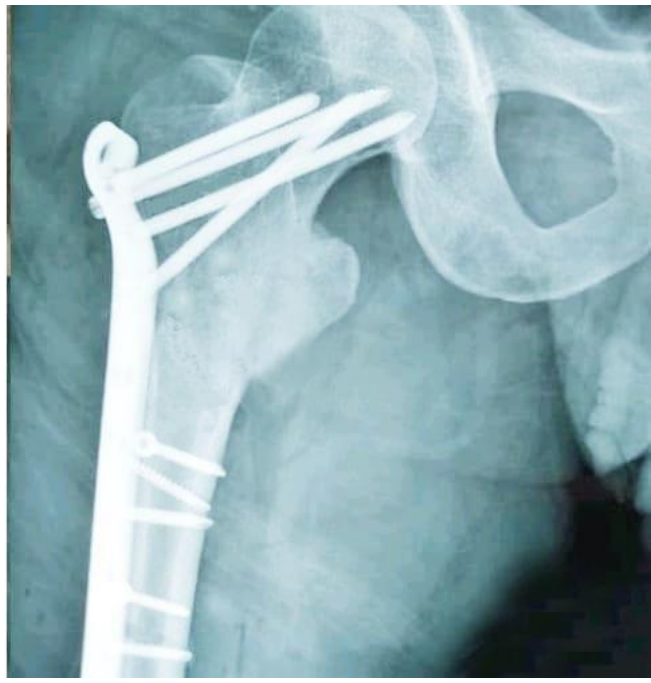

D

$\begin{array}{ll}\text { B) Postoperative x-ray } & \text { C) } 6 \text { months postoperative }\end{array}$ D) 26 months postoperative $x-$ ray

the subsequent gathering was overseen by LP. The two gatherings had a mean time of 57.7 and 59.3 years separately. No measurably critical distinction was identified between the two gatherings with respect to age $(p=0.297)$.

Another investigation remembered 20 cases for the PFN bunch with a mean time of 55.9 years, while the 20 cases in the LP bunch was having a mean age of 61 years [11].

In this investigation, 4 guys were incorporated $(40 \%)$ and 6 females $(60 \%)$ in the PFN gathering, though the LP bunch included 5 guys and 5 females (half). Like age, sexual orientation didn't establish a critical distinction between the two investigation gatherings ( $\mathrm{p}=$ 0.283). 
Another investigation remembered 16 guys and 29 females for the PFN gathering, though they remembered 17 guys and 25 females for the other gathering $(\mathrm{p}=0.636)$ [12]. Like our examination, no huge distinction was identified between the two gatherings with respect to sexual orientation.

Considering previous comorbidities in this examination, both diabetes and hypertension were available in $3(30 \%)$ and 4 (40\%) cases in PFN and LP bunches individually. The rest of the cases were having both of the recently referenced illnesses, or constant kidney malady. There was a factually noteworthy contrast between the two gatherings with respect to this point of view ( $p$ $=0.134)$.

In another examination performed to survey LP, eight patients were diabetic, four patients were hypertensive, and three were cardiovascular [13].

In the current investigation, the employable time was fundamentally longer in the bolted plate gathering (78 versus 52 minutes in PFN gathering $-\mathrm{p}=0.009$ ).

Another investigation revealed a more drawn out employable time for the LP activity contrasted with our outcomes. Creators revealed that the mean employable time was 131.5 minutes [14].

Wang et al. contemplated the clinical results of intramedulary (IM) obsession and LP in trochanteric cracks in old patients. They presumed that entry point length and usable time were shorter for the intramedulary obsession (IMF) than for LP [15].

Morever, Tao et al. analyzed less intrusive adjustment framework 'LISS' and PFN in the treatment of trochanteric breaks. They announced shorter employable time in the PFN gathering (66.9 versus 92.9 minutes in the other gathering $-\mathrm{p}<0.001)$ [12]. This concurs with this investigation results.

In this examination, albeit two cases in the bolted plate bunch got intra-employable blood bonding versus no cases in the other gathering, it was factually unimportant $(\mathrm{p}=0.081)$.

In this examination, albeit two cases in the bolted plate bunch got intra-employable blood bonding versus no cases in the other gathering, it was factually unimportant ( $p$ $=0.081$ ).

Another examination revealed no distinction in blood misfortune between the two procedures [12]. his comes in accordance with our outcomes.

On the other hand in another investigation, intraoperative blood misfortune, restoration, and time to mending were almost comparative among IMF and LP [15].
Taking a gander at the entry point length in this examination, it was essentially longer in the LP gathering (115 versus $60 \mathrm{~mm}$ in PFN gathering $-\mathrm{p}<0.001)$.

Another investigation revealed that the cut length for the LP bunch was $16.6 \mathrm{~cm}$ (extend, $12-30 \mathrm{~cm} 0$ [14].

Sharma and his partners revealed that the mean length of the careful cut utilized for PFN was $4.9 \mathrm{~cm}$ which is notably littler than the one utilized for LP [16].

With respect to twisted entanglements in the current investigation, it happened in just 1 case $(10 \%)$ in the femoral nail gathering, while it was experienced in 2 cases $(20 \%)$ in the other gathering $(\mathrm{p}=0.345)$.

Another examination detailed that shallow injury disease happened in 2 cases $(10 \%)$ in the PFN gathering, while it was experienced in 4 cases $(20 \%)$ in the LP gathering. Like our examination, DVT was not experienced in their cases during the post-usable period [11].

Another investigation revealed that no injury confusions occured in the PFN gathering [16].

Post-employable practical appraisal uncovered great HHS scores in the two gatherings. In spite of the fact that it was higher in the femoral nail gathering (score 88), no factually noteworthy distinction was seen between the two gatherings in regards to that issue $(\mathrm{p}=0.114)$.

Great outcomes were accomplished with both the converse LISS and PFN in each break type, which was as per the discoveries by Zhou et al. [17].

Tao and his partners detailed that HHS didn't contrast between the two gatherings. It had a mean of 82.8 and 82.0 in PFN and LP individually $(\mathrm{p}=0.717)$ [12].

In another examination directed in Egypt, mean Harris hip score (HHS) after LP was 62.3 at a half year which is reasonable and 81.2 at a year which is acceptable [13].

Zha et al., announced that treatment with LP can give great to astounding mending to pertrochantric femoral crack, with a constrained event of difficulties [18].

Veeragandham saw that PFNs demonstrate as progressively valuable in troublesome breaks with a sub-trochanteric augmentation or switched obliquity. They considered 40 patients with intertrochanteric break femur rewarded with PFN, DHS, and LP. They found that PFN was better than LP and DHS [11].

On follow up radiological assessment, postponed association was experienced in just 1 case in LP gathering (10\%), however it was not experienced in the other gathering. 
Radiological assessment as indicated by association of bone cortices uncovered great results in the two gatherings as they had a middle of 3 .

Different investigations have announced that the obsession with PFLP in instances of shaky trochanteric breaks can accomplish fulfilling radiological and clinical outcomes with a higher association rate and less inconveniences [19, 20].

Streubel et al. detailed that in patients with precarious 31 A3 trochanteric breaks rewarded with a LP, rates of reoperation (25\%), mechanical disappointment (38\%), and nonunion $(19 \%)$ were watched though these rates were $5 \%, 5 \%$, and $5 \%$ in patients rewarded with cephalomedullary nailing (CMN) [21].

In another investigation, the pace of association was comparative among PFN and LP [11].

In another investigation assessing LP in femoral cracks, thirteen patients (26\%) experienced embed disappointments including 7 plate breakages and 3 cases every one of screw breakage and cut-out [22]. None of these confusions were experienced in our investigation during the subsequent period.

With respect to, Zha et al. revealed study incorporating 110 cases with peri-trochanteric cracks and detailed one case each of nonassociation and embed breakage and 2 instances of disease [18]. Johnson et al. revealed $41.4 \%$ disappointment paces of which $83 \%$ patients were old females [23]. Gunadham et al. revealed $23 \%$ disappointment rate in a relative investigation of 26 patients with sub-trochanteric breaks including 2 broken plates, 1 broken screw, 1 nonassociation and 2 varus breakdown [24].

On the other hand, Saini et al. revealed no embed disappointment in their examination incorporating 32 patients with sub-trochanteric breaks who were treated with LP despite the fact that they detailed 2 instances of postponed association and disease every, two patients with appendage shortening and one with outside revolution distortion. This concurs with this examination results [25].

Remembering the decrease of mechanical disappointment chance, keep away from early weight-bearing after treatment with LP was suggested by numerous analysts. Furthermore, [6] R.F.Vasanwala, A.Sanghrajka, N.J. Bishop. Recurrent proximal femur fractures in a teenager with osteogenesis imperfecta on continuous bisphosphonate therapy: are we overtreating? J.,Bone and Mineral Research.Vol. 31(7),PP. 1449-1454,2016. expanding the size of the screws and giving a poly-pivotal situation to the proximal locking screws may give greater strength to the proximal part [26].

Concerning difficulties in the writing, in a progression of 191 breaks, Simmermacher et al., announced a general specialized disappointment pace of 4.6\% [27] In another investigation including 178 patients, Appelt et al revealed an entanglement pace of $15.2 \%$ $(\mathrm{n}=27) .(28)$ For a situation arrangement including 47 peritrochanteric cracks, Fogagnolo et al., discovered mechanical disappointments in $23.4 \%$ patients $(n=11)$ [29].

For another situation arrangement including 80 patients, Akan et al watched specialized difficulties in $10 \%$ patients $(n=8)$ [30]. In a forthcoming report incorporating 55 patients rewarded with PFN, Boldin et al., revealed a complexity pace of $21.8 \%$ patients $(n=12)[31]$.

\section{References}

[1] M. Liu, Z.Yang, F.Pei. A meta-analysis of the Gamma nail and dynamic hip screw in treating peritrochanteric fractures. International orthopaedics.vol .34(3),pp .323-328,2010.

[2] K.C.Roberts, W.T.Brox, D.S.Jevsevar. Management of hip fractures in the elderly. JAAOS-J.,the American Academy of Orthopaedic Surgeons.Vol. 23(2),PP.131137,2015 .

[3] C.C.Sidler-Maier, J.P.Waddell. Incidence and predisposing factors of periprosthetic proximal femoral fractures: a literature review. International orthopaedics.Vol.39(9),PP. 16731682,2015 .

[4] R.E.S.Pires, E.F.Prata, A.V.Gibram. Radiographic anatomy of the proximal femur: correlation with the occurrence of fractures. Acta ortopedica brasileira.Vol. 20(2),PP.79,2012.

[5] M.Anil. The use of an Intramedullary Nail vs. Dynamic Hip Screw in the treatment of Intertrochantric fractures; a case cohort study. Kerala J.,Orthopaedics.Vol. 25(1),2012.

[7] S.S.Konde S. S., Borkar, R.Shinde. Dynamic Hip Screw and Proximal Femoral Nail as a Mode of Surgical Treatment in Intertrochanteric Fractures of Femur in Elderly Patients. J.,Contemporary Medical Research.Vol. 5(4),PP. D4-D7,2018. 
[8] C.Jonnes, S.Shishir, S.Najimudeen. Type II intertrochanteric fractures: proximal femoral nailing (PFN) versus dynamic hip screw (DHS). Archives of Bone and Joint Surgery.Vol. 4(1),PP.23,2016.

[9] A.M.Nyholm, H.Palm, H.Malchau. Lacking evidence for performance of implants used for proximal femoral fractures-a systematic review. Injury.Vol. 47(3),PP.586-594,2016.

[10] B.Wang, Q.Liu, Y.Liu. Comparison of Proximal Femoral Nail Antirotation and Dynamic Hip Screw Internal Fixation on Serum Markers in Elderly Patients with Intertrochanteric Fractures. J.,the College of Physicians and Surgeons Pakistan.Vol. 29(7),PP. 644-648. ,2019.

[11] P.Veeragandham, R.K.Sahu. Comparative study between proximal femoral nailing and dynamic hip screw with proximal femoral locking compression plates in intertrochanteric fracture of femur. Int J Res Orthop.Vol. 3(3),PP. 339349,2017.

[12] R.Tao, Y.Lu, H.Xu. Internal fixation of intertrochanteric hip fractures: a clinical comparison of two implant designs. The Scientific World Journal,2013.

[13] M.S.M.Ismail, M.A.Ibrahim. Functional and radiological outcome of proximal femoral locking compression plates in the treatment of unstable trochanteric fractures. The Egyptian Orthopaedic Journal.Vol. 53(2),PP.103,2018.

[14] S.He, B.Yan, J.Zhu. High failure rate of proximal femoral locking plates in fixation of trochanteric fractures. J.,orthopaedic surgery and research.Vol.13(1),PP. 248,2018.

[15] Y.Wang, Y.Yang, Z.Yu. Comparative study of intertrochanteric fractures treated with proximal femur locking compress plate in aged. Zhongguo gu shang= China J.,orthopaedics and traumatology.Vol.24(5),PP.370-373,2011.

[16] A.Sharma, A.Sethi, S.Sharma. Treatment of stable intertrochanteric fractures of the femur with proximal femoral nail versus dynamic hip screw: a comparative study. Revista brasileira de ortopedia.Vol.53 (4),PP.477-481,2018.

[17] N.Han, G.x. Sun, Z.c.Li. Comparison of proximal femoral nail antirotation blade and reverse less invasive stabilization system?distal femur systems in the treatment of proximal femoral fractures. Orthopaedic surgery.Vol. 3(1),PP. 713,2011.
[18] G.C.Zha, Z.L.Chen, X.-B.Qi. Treatment of pertrochanteric fractures with a proximal femur locking compression plate. Injury.Vol. 42(11),PP. 1294$1299,2011$.

[19] A.C.Dhamangaonkar, D.Joshi, A.B.Goregaonkar.Proximal femoral locking plate versus dynamic hip screw for unstable intertrochanteric femoral fractures. J.,Orthopaedic Surgery .Vol.21(3),PP. 317$322,2013$.

[20] P.A.Sasnur, I.Hathiwale, A.SasnurSurgical outcome of proximal femoral fractures using proximal femorallocking compression plate. Al Am een J Med Sci.Vol. 8(3),PP. 235-238,2015.

[21] P.N. Streubel, M.J. Moustoukas, W.T.Obremskey. Mechanical failure after locking plate fixation of unstable intertrochanteric femur fractures. J.,orthopaedic trauma.Vol. 27(1),PP. 2228,2013

[22] A.Zubairi, R.H.Rashid, M.Zahid. Proximal Femur Locking Plate for SubTrochanteric Femur Fractures: Factors Associated with Failure. The open orthopaedics journal.Vol. 11,PP. 1058,2017.

[23] B.Johnson, J.Stevenson, R.Chamma. Short-term follow-up of pertrochanteric fractures treated using the proximal femoral locking plate. J.,orthopaedic trauma.Vol. 28(5),PP. 283-287,2014.

[24] U.Gunadham, J.Jampa, S.Suntornsup. The outcome in early cases of treatment of subtrochanteric fractures with proximal femur locking compression plate. Malaysian orthopaedic journal.Vol.8(2),PP. 22. ,2014.

[25] P.Saini, R.Kumar, V.Shekhawat. Biological fixation of comminuted subtrochanteric fractures with proximal femur locking compression plate. Injury.Vol. 44 (2),PP. 226-231,2013.

[26] C.Wirtz, F.Abbassi, D.Evangelopoulos. High failure rate of trochanteric fracture osteosynthesis with proximal femoral locking compression plate. Injury.Vol.44 (6) ,PP. 751-756,2013.

[27] R.Simmermacher, A.Bosch, C.Van der Werken. The AO/ASIF-proximal femoral nail $(\mathrm{PFN})$ : a new device for the treatment of unstable proximal femoral fractures. Injury.Vol. 30(5),PP. 327332,1999 . 
[28] A.Appelt, N.Suhm, M.Baier. Complications after intramedullary stabilization of proximal femur fractures: a retrospective analysis of 178 patients. European J.,Trauma and Emergency Surgery.Vol.33(3),PP. 262-267,2007.

[29] F.Fogagnolo, M.Kfuri, C.A.J.Paccola. Intramedullary fixation of pertrochanteric hip fractures with the short AO-ASIF proximal femoral nail. Archives of orthopaedic and trauma surgery.Vol.124(1),PP. 31-37,2004.
[30] K.Akan, H.Cift, K.Ozkan. Effect of osteoporosis on clinical outcomes in intertrochanteric hip fractures treated with a proximal femoral nail. J.,International Medical Research.Vol. 39(3),PP. 857$865,2011$.

[31] C.Boldin, F.J.Seibert, F.Fankhauser. The proximal femoral nail (PFN)-a minimal invasive treatment of unstable proximal femoral fractures: a prospective study of 55 patients with a follow-up of 15 months. Acta Orthopaedica Scandinavica. Vol.74 (1),PP. 53-58. 2003. 